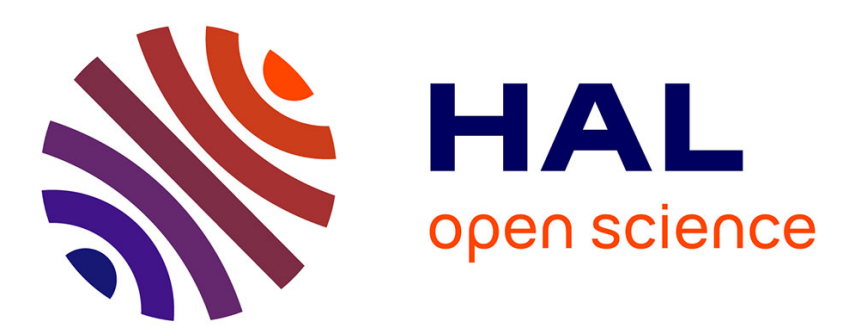

\title{
Transport, health and climate change: Deciding on the optimal policy
}

Laure Cabantous, Olivier Chanel, Jean-Christophe Vergnaud

\section{To cite this version:}

Laure Cabantous, Olivier Chanel, Jean-Christophe Vergnaud. Transport, health and climate change: Deciding on the optimal policy. 2010. halshs-00543966

\section{HAL Id: halshs-00543966 \\ https://shs.hal.science/halshs-00543966}

Preprint submitted on 7 Dec 2010

HAL is a multi-disciplinary open access archive for the deposit and dissemination of scientific research documents, whether they are published or not. The documents may come from teaching and research institutions in France or abroad, or from public or private research centers.
L'archive ouverte pluridisciplinaire HAL, est destinée au dépôt et à la diffusion de documents scientifiques de niveau recherche, publiés ou non, émanant des établissements d'enseignement et de recherche français ou étrangers, des laboratoires publics ou privés. 


\section{GREQAM}

Groupement de Recherche en Economie Quantitative d'Aix-Marseille - UMR-CNRS 6579

Ecole des Hautes études en Sciences Sociales Universités d'Aix-Marseille II et III
Document de Travail $n^{\circ} 2010-50$

Transport, health and climate change:

Deciding on the optimal policy

\author{
Laure CABANTOUS \\ Olivier CHANEL \\ Jean-Christophe VERGNAUD
}

December 2010 


\title{
Transport, health and climate change: Deciding on the optimal policy*
}

\author{
Laure Cabantous $^{1}$ Olivier Chanel ${ }^{2}$ and Jean-Christophe Vergnaud ${ }^{3}$
}

27th April 2010

\begin{abstract}
Transport generates many externalities, some related to atmospheric pollution. In this paper, we focus on two: greenhouse gases, and local pollution. In the search for optimal transport policies, these two externalities have usually been analysed separately. Here, we study them jointly, in a sequential decision-making model. Our model allows for the irreversibility of the policies undertaken, as well as the possibility of a progressive reduction of uncertainties with the arrival of information. We find that when both sources of externalities are analysed jointly, structural measures enabling private transport requirements to be reduced are identified as being more advantageous economically than technological measures to reduce emissions of pollutants. We illustrate the usefulness of a joint analysis of externalities with two examples: tax measures on cars and housing policy.
\end{abstract}

Keywords: climate change, model of decision-making under uncertainty, irreversibilities, transport policy.

JEL code: C6, D62, D81, R48

\footnotetext{
* Authors thank two anonymous referees for helpful comments and suggestions and Marjorie Sweetko for her translation of this article into English. They also tank participants at the University Paris 1 seminar, 2009 for comments on an earlier version of the paper. Financial support of French Research National Agency (ANR-08RISKNAT-007-01 RISKEMOTION) is gratefully acknowledged.

${ }^{1}$ Nottingham University Business School, Jubilee Campus, Wollaton Road, NG8 1BB, Nottingham, UK, Tel: 44 (0)115 8468486; e-mail: laure.cabantous@nottingham.ac.uk.

${ }^{2}$ Corresponding author: GREQAM-CNRS-IDEP, 2 Rue de la Charité, 13002 Marseille, Tel: 33 (0)4 911407 80; e-mail: chanel@univmed.fr.

${ }^{3}$ CES-CNRS, 106-112, Bld de l'Hôpital, 75647 Paris, Cedex 13, Tel: 33 (0)1 554342 29; e-mail: JeanChristophe.Vergnaud@univ-paris1.fr.
} 


\section{Introduction}

Beyond their primary vocation, which is to carry goods and people, our means of transport produce numerous harmful effects and generate considerable externalities (CGP, 2001; InfrasIWW, 2004; Mailbach et al., 2008). They are responsible for road congestion, landscape disturbance and road accidents. Moreover, they contribute to a deteriorating environment in terms of noise levels, aesthetics and atmospheric pollution (greenhouse gas emissions and local pollutants). ${ }^{4}$

The impact of transport with respect both to climate change (greenhouse gas emissions, or GGEs) and to local air pollution (particles, $\mathrm{NO}_{\mathrm{X}}$ ) is a particularly topical issue. In both cases, progress on fixed-source emissions has actually led to transport becoming the prime source of GGEs: it produced an average of 21\% of emissions by the European Union-15 (EU-15), in 2005 (European Environment Agency, 2007). ${ }^{5}$ Transport is also the prime emitter of local, health-damaging pollutants, producing 36\% of total particle emissions in 2007 (European Environment Agency, 2009a). Finally, transport is the major source of emissions of $\mathrm{NO}_{\mathrm{X}}$, generating some 50\% of total emissions in 2007 (European Environment Agency, 2009b). Road transport accounts for roughly two-thirds of particle and $\mathrm{NO}_{\mathrm{X}}$ emissions, as well as $90 \%$ of GGEs of all transport emissions.

Although local pollution and climate change share the same source, they have often been analysed separately when pricing policies for transport are determined. In France, for example, the government-organised public forum on the environment (Grenelle de l'Environnement) recommended introducing a tax system based on both $\mathrm{CO}_{2}$ and particle emissions ("Eco-pastille"). This system, however, was adopted only for $\mathrm{CO}_{2}$. Similarly, in the United Kingdom, where the Department of Transport $(1998,2008)$ has been pleading for over ten years for joint management of transport and environmental policies, local pollutants and GGEs are analysed separately (Begg and Gray, 2004).

Moreover, to date most debates on policies for reducing atmospheric pollutant emissions from transport have not satisfactorily taken into account the prevailing major uncertainties, be they scientific (the extent of environmental change), economic (the method of evaluating the costs of externalities) or technical (the effectiveness of pollution cleanup policies). Thus, in 2000, when the French government was updating its recommended reference values for the costs of effects ("valeurs tutélaires"), in order to take into account the external costs of transport (CGP, 2001), the two Ministries responsible for the environment and for transport disagreed over the value of a tonne of $\mathrm{CO}_{2}$ and the health costs of exposure to air pollution. The Ministry for the Environment pleaded for much higher values than the Ministry for Transport. The latter cited the great uncertainty involved in the evaluation of externalities to defend lower valuations. Since these reference values are intended to be applied when assessing infrastructure projects, higher values would have a particularly favourable impact on the development of public transport systems. More recently, similar differences emerged in the debate on the updating of the value of a tonne of $\mathrm{CO}_{2}$ (Centre d'analyse stratégique, 2009)

\footnotetext{
${ }^{4}$ Greenhouse gases include $\mathrm{CO}_{2}, \mathrm{CH}_{4}, \mathrm{~N}_{2} \mathrm{O}, \mathrm{CF}_{4}, \mathrm{C}_{2} \mathrm{~F}_{6}$ and $\mathrm{SF}_{6}$. They are usually expressed in $\mathrm{CO}_{2}$ equivalent or global warming potential for the purposes of analysis.

${ }^{5}$ GGEs from the transport sector increased by 25.5\% between 1990 and 2005, while emissions from all other sources decreased by $7 \%$ over the same period.
} 
and on the amount of the "climate and energy contribution" tax (Conférence des experts sur la contribution Climat et Energie, 2009).

A fuller grasp of the uncertainties, influenced less by special interests, thus seems to be needed. Given this context, it appears relevant to place uncertainty in a dynamic framework. This requires a sensitivity analysis, clarifying to what extent the values adopted impact on the effectiveness of policies. It also means that policy choices will be conditioned by the effects of the arrival of information. For instance, different policies for reducing atmospheric pollution could be compared, while taking into account the arrival of information showing that the negative effects of one of these externalities are more important than expected.

In this article, we present a model to support public decision-making in the field of transport policy. Our model has the advantage of jointly considering both types of atmospheric pollution generated by transport (GGEs and particle pollution which we will use as an indicator of local pollution). It also includes the principal characteristics of the context with respect to uncertainty and irreversibilities, thus providing scope for taking into consideration the effect of the arrival of information to influence the choice of policies. The model shows that when both sources of externalities are analysed jointly, structural measures enabling private transport requirements to be reduced are more advantageous economically than technological measures aimed at reducing emissions of pollutants.

The article begins with a description of the decision-making context. We then present the general hypotheses of the model in Part 3. Part 4 gives the principal findings. We discuss and illustrate the concrete implications of this model in Part 5. Part 6 concludes.

\section{The decision-making context: Uncertainty and irreversibilities in transport}

The debate over policies for reducing emissions of atmospheric pollutants by transport is complicated by the existence of numerous uncertainties. Despite major advances in the body of knowledge on climate change and local pollution, there are persistent scientific, economic and technological uncertainties about the effects of GGEs and particle pollution.

Moreover, both these types of pollution have the effect of producing economic and/or ecological irreversibilities: i.e. they lead to alterations in the ecological and/or economic systems such that it becomes impossible subsequently to return to the initial state. Since no future action will enable a return to starting point, the decision-maker has to take into account, from the outset, the potential effects of the policies that s/he plans to conduct. Irreversibilities therefore complicate the decision-making process, suggesting that the decision-maker should be placed in a dynamic framework with the arrival of information enabling him/her to allow for the value of expected information (called quasi-option value or information option value). 


\subsubsection{Scientific uncertainties about GGEs}

Both the nature and extent of the greenhouse effect and the consequences of GGEs are highly controversial (see for instance Michaels, 2005 or Singer, 2008).

\section{Uncertainties about the extent of climate change}

With the object of estimating the extent of climate change, numerous scenarios using complex models of evaluation based on various hypotheses (climate sensitivity, thermal inertia in oceans, net balance of carbon sinks, etc.) have been proposed. Whatever the standpoint, it is estimated that the rate of climate change will be faster than any other change experienced over the past 10,000 years (Godard and Henry, 1998).

Beyond this certainty, it remains very difficult to estimate precisely the extent of climate change, so that scientific studies usually give a range of values. For example, the Fourth Report of the Intergovernmental Panel on Climate Change (IPCC) estimates that if no action is taken, there will be an increase in global temperatures of between 1.1 and $6.4^{\circ} \mathrm{C}$ by the end of the $21^{\text {st }}$ century, compared to the $1990-99$ period. It further predicts an increase in the sea level ranging from $18 \mathrm{~cm}$ to $59 \mathrm{~cm}$ (IPCC, 2007) and a decrease in rainfall of roughly $15 \%$ between latitudes $30^{\circ} \mathrm{N}-55^{\circ} \mathrm{N}$ and latitudes $0^{\circ}-20^{\circ} \mathrm{S}$.

\section{Uncertainties about the consequences of climate change}

Estimating the consequences of an increase in the mean temperature of the planet is also difficult, since this brings into play a number of factors such as relief, proximity to a body of water or latitude. While there is a relative consensus on the potential consequences of climate change (changes to temperature distribution, increase in the frequency and intensity of natural disasters and contagious diseases), scientific studies do not offer a precise estimation of these consequences. The public decision-maker thus has to decide on the basis of scientific reports which, while rigorously compiled, contain loose estimates of the consequences of climate change. For example, the scientific studies concerning France conclude that climate change will bring about changes to rainfall varying from $-20 \%$ to $+50 \%$, depending on location and season.

Moreover, while the scientific studies all conclude that these alterations will have major economic impacts on the fields of insurance, tourism, agriculture, health, the extent and the timing of these effects have not been precisely determined. The IPCC report (2007) estimates the socio-economic cost of a $4^{\circ} \mathrm{C}$ rise in temperature at between 1 and $5 \%$ of Gross National Product. It evaluates the actualised net economic cost of the damage caused by global change at $\$ 12 /$ tonne of $\mathrm{CO}_{2}$ in 2005, with a range of $\$ 3$ to $\$ 95 /$ tonne of $\mathrm{CO}_{2}$ (IPCC, 2007).

\subsubsection{Scientific uncertainties about particles}

The scientific uncertainties surrounding particles are more limited than those surrounding GGEs. The processes by which particle pollution affects health and buildings, for example, 
have already been established. Scientific studies have revealed two major health risks: respiratory and cardiovascular morbidity and short-term mortality (WHO, 2005).

However, this does not mean that particle pollution carries no scientific uncertainties. Its consequences in terms of morbidity and long-term mortality, as well as on the determination of number of life years lost, for example, are not yet fully understood. There are also uncertainties concerning the harm to health caused by particles as a function of their source, their size and their chemical composition (Hüglin and Gehrig, 2000; Samoli et al., 2006). Moreover, these uncertainties are added to those arising from the transfer of ExposureResponse functions (established for certain geographic zones) to other geographic zones for which specific data are not available.

Finally, there are uncertainties over obtaining the full, expected benefit from a particular technological measure (such as particle filters). The composition of atmospheric pollution is constantly changing (under the impetus of technological evolution and changes in air pollution standards) and the indicators measured are just one piece of the picture which, it is hoped, are as representative as possible. ${ }^{6}$ Since they come from the same sources and are subject to the same conditions of dispersion by weather, measurements of the concentrations of numerous pollutants are strongly correlated. This leads to the risk of attributing excessive environmental and health damage to a particular pollutant, because it is measured more efficiently, and, as a corollary, underestimating the contributions of the other, associated pollutants. This type of uncertainty, however, disappears when there is a simultaneous reduction in all emissions.

\subsubsection{Economic and technological uncertainties}

In addition to scientific uncertainties about physical phenomena, the public decision-maker faces technological uncertainties linked to estimating the effectiveness of pollution cleanup measures. For example, it is clear that developing electric vehicles will eliminate local pollution, but the results in terms of GGEs are more mixed, and will depend on whether or not fossil fuels are used to produce the electricity.

Finally, the public decision-maker faces uncertainties of an economic nature when seeking to evaluate the costs of the externalities. These economic uncertainties arise essentially from the choice of methodology. The decision-maker can choose from various methods of evaluating harm, from various monetary values (cost of a morbidity episode, inability to work, the value of human life, damage to buildings, impacts on agriculture) and various discount rates. Taken together, these choices have major consequences on decisions, so that methodology is often the subject of lively political debate, as illustrated by the discussions on the CGP (2001) report on reference values in France. Certain approaches, however, are leading to a relative homogenisation and stabilisation in methodology: for example, the New Elements for the Assessment of External Costs of Energy Technologies (NewExt, 2004) or Clean Air for Europe (CAFE, 2005).

\footnotetext{
${ }^{6}$ Up until the introduction of unleaded petrol, "atmospheric lead content" acted as a good measure of automobile-generated pollution. The disappearance of lead did not, however, lead to the disappearance of automobile-generated pollution, nor of the associated health hazards.
} 


\subsection{The irreversibilities}

It is common practice to distinguish between irreversibilities of an ecological nature and those of an economic nature. In this paper, ecological irreversibilities only concern GGEs. Current emissions are adding to an atmospheric stock which is very slow to dissipate. For instance, Devolder (2008) estimates that $50 \%$ of $\mathrm{CO}_{2}$ emitted disappear in 30 years, a further $30 \%$ in a few centuries and the remaining $20 \%$ in a few millennia. If we want to limit global warming to $2^{\circ} \mathrm{C}$, we will have to decrease total world-wide greenhouse gas emissions by between $50 \%$ to $85 \%$ by 2050 (Devolder, 2008). In terms of the life span of a human being, therefore, the phenomenon can effectively be considered irreversible, and the whole range of potential strategies needs to be considered from a 20- to 50-year perspective. Conversely, particle pollution is not actually irreversible: ${ }^{7}$ mean particle concentrations in the air can decrease rapidly (by $90 \%$ in a few days); thus natural regeneration is fairly rapid and there is no problem of stock build ups.

The economic irreversibilities connected with GGEs and with particle pollution concern the costs entailed in putting policies into practice. Transport use is closely linked to lifestyle, so that implementing a fundamental policy takes a relatively long time and probably involves sunk costs.

Thus, climate change appears to be a unique phenomenon affecting the whole planet (with the problems of coordination that this implies) and involving a long time horizon (with the attendant problem of discounting). In addition, it brings into play both irreversibilities and the possibility of uncertainties being progressively reduced through the arrival of information. All these features argue for it to be treated within the framework of economic theory relating to decision-making, under uncertainty with an irreversibility effect (Arrow and Fisher, 1974; Freixas and Laffont, 1984; Henry, 1974). Particle pollution, on the other hand, seems adequately characterised. Thus, the relative stabilisation of the economic evaluations of health costs means that it can be considered as relatively well-known, and hence certain.

\section{The Model: A Reduced Representation of Transport Economics}

We present a sequential model to support decision-making. This model is a reduced representation of transport economics, in which the public decision-maker can control different decision variables in order to regulate emissions of pollutants from transport. ${ }^{8}$ The model has two periods, which makes it possible to take into consideration the effect of an arrival of information on the choice of policies. It focuses on two pollutants (GGEs and particle pollution) and considers the two major types of public sector policies currently under consideration in most countries: technological measures and structural measures. In essence, this stylised model, designed along the lines of the models introduced by Arrow-Fisher (1974) and Henry (1974), highlights in a didactic manner the logical arguments in favour of one or the other of the policies.

\footnotetext{
${ }^{7}$ However, from the point of view of those people affected by particle pollution, it can appear irreversible insofar as it can cause premature death.

${ }^{8}$ Since the public decision-maker is the only agent explicitly considered in this model, this model reduces to an individual decision-making model.
} 


\subsection{General structure of the model}

In order to take into account the arrival of information and the irreversibilities involved in climate change and particle pollution, the model covers two periods, $t=1,2$. During each of the two periods, the public decision-maker can take action using the three decision variables at his/her disposal:

- the proportion of journeys made in private vehicles $V_{t}$ (the proportion of journeys made using public transport naturally being complementary $1-V_{t}$ ),

- the rate of reduction of GGEs $G_{t}$,

- the rate of reduction of particle pollution $P_{t}$.

Taking the proportion of journeys made in private vehicles $V_{t}$ as a decision variable, we assume that the decision-maker can choose the equilibrium level in the transport market. In addition, as we are dealing with the proportion of journeys made either in private or public transport, we therefore also assume that there is a fixed volume of kilometres covered by an individual. This strong assumption is intended to simplify analysis. We would otherwise have to introduce a collective utility function dependent on total volume. Adding this feature to the model however, would make no difference to the qualitative results on the optimal internalisation of pollution.

These three decision variables concern both the structural and technological types of policy available to the public decision-maker attempting to regulate atmospheric pollution.

The first variable is the product of structural measures: the number of kilometres covered in private road transport is altered, thus affecting overall externalities. Such policies aim at, for example, increased car-sharing, reduced city centre access and parking, as well as more efficient public transport. The public decision-maker is absolutely free to choose how policies are implemented (urban tolls, enlarged public transport networks, special traffic lanes reserved for vehicles carrying at least three people, increased taxes on all fuels). Because these policies affect total emissions, they are less sensitive to uncertainty than technological measures.

The other two variables for the reduction of emissions of pollutants concern technological measures targeting the emission rates of pollutants per kilometres travelled. These are, for example, policies aimed at improving technologies like particle filters or $\mathrm{NO}_{\mathrm{X}}$ filters; at renewing the car fleet with less polluting vehicles (low-emission or zero-emission levels) or at traffic management (speed limits). These technological policies can be implemented in various ways, by imposing standards on fuels, through green tax incentives, through the "Ecopastille" system. However, these measures have limitations, generally targeting emissions from a single pollutant $\left(\mathrm{CO}_{2}, \mathrm{SO}_{2}\right.$, particles, $\left.\mathrm{NO}_{\mathrm{X}}\right)$. Moreover, the gains obtained from technological improvements can very easily be partially lost following an increase in the 
volume of individual journeys, for instance. ${ }^{9}$

\subsection{The objective function of the public decision-maker}

In order to take both types of policy into account, the objective function of the public decision-maker needs to distinguish between costs associated with structural policies and costs associated with technological policies. Formally, the public decision-maker is looking to minimise the total social costs of transport, which can be broken down as follows:

\section{Total costs $=$ Variable costs of transport + Pollution cleanup costs + Pollution costs}

- The variable costs of transport are given by a function $\alpha . V_{t}+C\left(1-V_{t}\right)$ where $C($.$) is$ differentiable and convex. $\alpha$ is a unit cost per km travelled in a private vehicle. ${ }^{10}$

- Pollution cleanup costs are linked to technological measures and can be broken down into two parts. The linear part $\left(\beta \cdot G_{t}+\gamma \cdot P_{t}\right) \cdot V_{t}$ represents variable costs where $\beta(\gamma)$ is the unit cost per $\mathrm{km}$ travelled of a total reduction in GGEs (particle emissions). The non-linear part $D\left(G_{t}\right)+E\left(P_{t}\right)$ represents the fixed costs which are taken to be positive, increasing and convex.

- The costs of the pollution vary with the proportion of individual journeys: $\left(\theta .\left(1-G_{t}\right)+\phi \cdot\left(1-P_{t}\right)\right) \cdot V_{t}$ where $\theta(\phi)$ represents the extra cost per GGE (particle) unit of pollution emitted from a private vehicle as compared to public transport. We consider the rates of emissions per passenger-kilometre from public transport to be lower than those from private vehicles. We also assume that whatever the values taken by $\theta$ and $\phi$ in the model, we still have $\theta \geq \beta$ and $\phi \geq \gamma$ and that therefore any attempt at pollution cleanup is always effective.

In the end, the function of the total cost that the public decision-maker has to minimise at $t=$ 1,2 is the following:

$$
\begin{aligned}
C T\left(V_{t} ; G_{t} ; P_{t} ; \theta ; \phi\right)= & \alpha \cdot V_{t}+C\left(1-V_{t}\right) \\
& +\left(\beta \cdot G_{t}+\gamma \cdot P_{t}\right) \cdot V_{t}+D\left(G_{t}\right)+E\left(P_{t}\right) \\
& +\left(\theta \cdot\left(1-G_{t}\right)+\phi \cdot\left(1-P_{t}\right)\right) V_{t} .
\end{aligned}
$$

This cost function has the advantage of being relatively simple, while realistically synthesising the genuine social costs generated by transport. Operational applications would no doubt require an adjusted version.

\footnotetext{
${ }^{9}$ The results of a study by the European Environment Agency (2000) on the evolution of energy efficiency in transport since the beginning of the 1970s are instructive. Although engines have become more fuel-efficient (using roughly 30\% less fuel), the energy used per passenger-kilometre in car transport has remained constant. The fact is that this period has witnessed increased traffic congestion, fewer passengers per car, increased car weight (in the same categories), and shorter average car journeys.

${ }^{10}$ To suppose that private transport costs are linear $\left(\alpha V_{t}\right)$ is probably unrealistic. However, it should be noted that a convex function in $\left(1-V_{t}\right)$ is formally equivalent to a concave function in $V_{t}$. Hence, the function $C($.) can formally take account of concave costs for private transport, which is fairly realistic (amortisation of vehicle purchasing costs by households decreases with the total number of kilometres travelled, for example).
} 


\subsection{Uncertainty and information}

We take into account the fact that the public decision-maker has to decide on a policy to reduce emissions of pollutants from transport, even though s/he is aware that there are uncertainties about the consequences of the emission of these pollutants. We have already mentioned that the main uncertainties concern the values of the costs connected with GGEs. Hence, our analysis focuses on these values.

Formally, we use $\bar{\theta}$ and $\bar{\phi}$ to denote the expected supplementary costs per unit of GGE and of particle pollution respectively. In the case of GGEs, we assume that this cost can be higher or lower (with equal probability) by an amount $\varepsilon$ with $\varepsilon<\bar{\theta}$ (this assumption excludes the possibility of discovering that climate change is economically favourable).

Moreover, we assume that the public decision-maker is able to learn the exact costs of GGEs between period 1 and period 2 and we call $g=0,1$ the indicator of the arrival of such information. This assumption makes it possible to study the impact that anticipating the arrival of information has on the optimal decision.

\subsection{Irreversibilities and intertemporal externalities}

In order to obtain a suitable representation of the situation, our model includes two types of decisional irreversibilities (or intertemporal externalities).

The first irreversibility concerns the decision about developing public transport. This kind of decision usually needs to be taken well in advance. Accordingly, a relevant assumption is that it will not be possible in the second period to adjust the proportion of public transport upwards: $1-V_{2} \leq 1-V_{1}$, that is $V_{2} \geq V_{1}$. This extreme assumption is consistent with certain structural decisions, such as development of heavy infrastructures for public transport (tramways, undergrounds), urban development policy involving a more or less denselypopulated habitat. We will call $i=0,1$ the indicator of the presence of such an irreversibility constraint: $V_{2} \in\left[i . V_{1} ; 1\right]$. This first intertemporal externality is induced from the fact that the costs of investments in public transport depend on the level of public transport in the preceding period. The indicator shows the presence $(i=1)$ or the absence $(i=0)$ of intertemporal investment costs.

The second irreversibility concerns the choices of rates of reduction of emissions $G_{2}$ and $P_{2}$ : $G_{2} \geq G_{1}$ and $P_{2} \geq P_{1}$. Indeed, these levels of emission reduction are usually fixed by environmental standards. Experience shows that there is no going back on environmental regulations (for example, the enforcement of the desulphurisation of diesel or the use of unleaded petrol), and that any changes always tend towards reinforcing standards, thus diminishing rates of emission. It can therefore justifiably be assumed that these standards will not be relaxed in the future. We introduce $c=0,1$ as an indicator of the presence of irreversibility constraints: 


$$
G_{t} \in\left[c . G_{t-1} ; 1\right], P_{t} \in\left[c . P_{t-1} ; 1\right], t=1,2
$$

\subsection{The reference solution}

To examine the effect of the arrival of information, we consider the optimal stationary solution in the absence of information as the reference situation. It is therefore not necessary to consider the sequential nature of the model, and the total cost function can simply be minimised over one period. We call this the optimal solution $\left(V^{*} ; G^{*}, P^{*}\right)$; it represents a situation where (i) marginal costs of private and public transport are the same, and (ii) marginal costs of pollution cleanup are the same as marginal profits. $\left(V^{*} ; G^{*}, P^{*}\right)$ is therefore the solution to the following system:

$$
\left\{\begin{array}{c}
\alpha+\beta \cdot G^{*}+\gamma \cdot P^{*}+\bar{\theta} \cdot\left(1-G^{*}\right)+\bar{\phi} \cdot\left(1-P^{*}\right)=C^{\prime}\left(1-V^{*}\right) \\
\beta \cdot V^{*}+D^{\prime}\left(G^{*}\right)=\bar{\theta} \cdot V^{*} \\
\gamma \cdot V^{*}+E^{\prime}\left(P^{*}\right)=\bar{\phi} \cdot V^{*}
\end{array}\right.
$$

This optimal stationary solution is not dependent on the presence of irreversibility constraints.

\section{The results}

We look at sequential choices over the two periods, with the arrival of information between Period 1 and Period 2.

To simplify the presentation of the results, we choose to eliminate two extreme cases which are unrealistic. The first entails the public decision-maker taking no pollution cleanup measures, so that we have a zero cost of pollution cleanup, and a maximum cost of extra pollution. The second case that we eliminate is where the public decision-maker reduces the proportion of private transport to zero, so that we get maximum cost of pollution cleanup and a zero cost of extra pollution.

Having eliminated these two unrealistic extreme cases, we seek an optimal intermediate solution. By definition, this optimal solution minimises overall total costs over the two periods. It should be noted that the second period costs may depend on decisions taken during the first period under irreversibility constraints $i=1$ and/or $c=1$ :

$$
J\left(V_{1} ; G_{1} ; P_{1} ; \theta ; \phi ; i ; c\right)=\underset{V_{2} \in\left[i . V_{1} ; 1\right], G_{2} \in\left[c . G_{1} ; 1\right], P_{2} \in\left[c . P_{1} ; 1\right]}{\operatorname{Min}} \operatorname{CT}\left(V_{2} ; G_{2} ; P_{2} ; \theta ; \phi\right)
$$

We use $\bar{J}\left(V_{1} ; G_{1} ; P_{1} ; \bar{\theta} ; \bar{\phi} ; i ; c ; g\right)$ to denote the anticipated value of the total optimal costs of the second period, conditional on the choices of the first period. Two cases are possible: 
- No information $(g=0)$ :

$$
\bar{J}\left(V_{1} ; G_{1} ; P_{1} ; \bar{\theta} ; \bar{\phi} ; i ; c ; 0\right)=J\left(V_{1} ; G_{1} ; P_{1} ; \bar{\theta} ; \bar{\phi} ; i ; c\right)
$$

- Information on climate change $(g=1)$ :

$$
\bar{J}\left(V_{1} ; G_{1} ; P_{1} ; \bar{\theta} ; \bar{\phi} ; i ; c ; 1\right)=1 / 2 .\left[J\left(V_{1} ; G_{1} ; P_{1} ; \bar{\theta}+\varepsilon ; \bar{\phi} ; i ; c\right)+J\left(V_{1} ; G_{1} ; P_{1} ; \bar{\theta}-\varepsilon ; \bar{\phi} ; i ; c\right)\right]
$$

The optimal choices of the first period are denoted $V_{1}^{*}(i ; c ; g), G_{1}^{*}(i ; c ; g)$ and $P_{1}^{*}(i ; c ; g)$. These optimal choices are the solution to the problem of minimising overall costs over the two periods:

$$
\operatorname{Min}_{V_{1} \in[0 ; 1], G_{1} \in\left[0 ; 1, P_{1} \in[0 ; 1]\right.} C T\left(V_{1} ; G_{1} ; P_{1} ; \bar{\theta} ; \bar{\phi}\right)+\bar{J}\left(V_{1} ; G_{1} ; P_{1} ; \bar{\theta} ; \bar{\phi} ; i ; c ; g\right)
$$

In the absence of information, even though two periods were considered, the optimal stationary solution is also the optimal solution to the problem of minimisation, whatever the nature of constraints $i$ and $c$ :

$$
\forall i, c V_{1}^{*}(i ; c ; 0)=V^{*}, G_{1}^{*}(i ; c ; 0)=G^{*}, P_{1}^{*}(i ; c ; 0)=P^{*}
$$

Similarly, anticipating information has no effect in the first period without irreversibility constraints $(i=c=0)$. The value function for the second period, $\bar{J}\left(V_{1} ; G_{1} ; P_{1} ; \bar{\theta} ; \bar{\phi} ; 0 ; 0 ; g\right)$, is thus independent of the decisions taken in the first period, and we obtain:

$$
\forall g, V_{1}^{*}(0 ; 0 ; g)=V^{*}, G_{1}^{*}(0 ; 0 ; g)=G^{*}, P_{1}^{*}(0 ; 0 ; g)=P^{*}
$$

Solving this model reveals two types of effects: effects related to the expectation of information and those related to the presence of irreversibility. We present the results concerning these two types of effects in the following subsection.

\subsection{The effects of expecting the arrival of information}

In models that take into account decisional irreversibilities and where there exists a quasioption value, expecting the arrival of information generally encourages the decision-maker to make more flexible choices (due to the irreversibility effect). Indeed, more flexible choices enable the decision-maker to use the information better.

Owing to the structure of the model detailed herein, an irreversibility effect is expected for the rates of emission reduction. In other words, greater flexibility is expected to result in lower rates of emission reduction as compared to the reference situation. Expecting the arrival of 
information on climate change leads to setting a reduction rate for GGEs in Period 1 which is lower than that of the stationary reference solution $\left(G_{1}^{*}(i ; c ; 1) \leq G_{1}^{*}(i ; c ; 0)\right)$.

Expecting an arrival of information leads not only to direct irreversibility effects but also to supplementary effects, as described in Proposition 1 below.

Proposition 1: When an arrival of information is expected, the optimal policy is to reduce the proportion of private transport and the reduction levels for emission rates of both pollutants:

$\forall i, c$ (1) $V_{1}^{*}(i ; c ; 1) \leq V_{1}^{*}(i ; c ; 0)$, (2) $G_{1}^{*}(i ; c ; 1) \leq G_{1}^{*}(i ; c ; 0)$, (3) $P_{1}^{*}(i ; c ; 1) \leq P_{1}^{*}(i ; c ; 0)$

Result (2) corresponds to the direct irreversibility effects usually encountered. The other results correspond to the supplementary effects and can easily be understood. Because there is a higher rate of emission for the pollutant concerned by the arrival of information, the marginal cost of private transport is increased compared to the reference situation and the optimal policy is to increase the proportion of public transport (Result (1)). In the process, the economic advantages from the pollution cleanup of the other pollutant (particles) are reduced, and the optimal policy is to reduce the level of reduction in emissions of this pollutant as well (Result (3)). The formal proof is contained in the Appendix.

\subsection{The effects of irreversibilities and intertemporal externalities}

Irreversibilities and investment costs have an effect comparable to that of information. If information arrives, $g=1$, irreversibility constraints lead to reducing simultaneously the proportion of private transport and the level of reduction of emissions.

Proposition 2: The introduction of irreversibility constraints leads to a lower proportion of private transport and lower levels of reduction in emission rates:

a) when these constraints concern the proportion of public transport:

$\forall c$, (1) $V_{1}^{*}(1 ; c ; 1) \leq V_{1}^{*}(0 ; c ; 1),(2) G_{1}^{*}(1 ; c ; 1) \leq G_{1}^{*}(0 ; c ; 1)$, (3) $P_{1}^{*}(1 ; c ; 1) \leq P_{1}^{*}(0 ; c ; 1)$.

(b) when these constraints concern the rates of emission reduction:

$\forall i$ (1) $V_{1}^{*}(i ; 1 ; 1) \leq V_{1}^{*}(i ; 0 ; 1)$, (2) $G_{1}^{*}(i ; 1 ; 1) \leq G_{1}^{*}(i ; 0 ; 1)$, (3) $P_{1}^{*}(i ; 1 ; 1) \leq P_{1}^{*}(i ; 0 ; 1)$

Irreversibility constraints introduce a problem of flexibility.

In the second period, if the information received indicates that environmental impacts are in the upper range, then the optimal policy will be to develop public transport. The irreversibility constraint concerning public transport will thus force the public decision-maker to take a more flexible decision in the first period, that is, to increase the proportion of public transport starting from the first period (Result (a-1)). Since the proportion of private transport is reduced, the economic advantages of pollution cleanup are also reduced, which explains Results (a-2) and (a-3). 
Those irreversibility constraints which concern rates of emission reduction pose a problem when the information received indicates that the impacts of climate change are in the lower range. To increase flexibility and allow the GGEs reduction rate to be adjusted downwards, the public decision-maker has to limit this emission reduction rate, starting from the first period (Result (b-2)). The marginal cost of private transport in the first period is thus higher, which explains Result (b-1), indicating that the proportion of private transport should be reduced. As a final consequence, the economic advantages from pollution cleanup are also reduced, explaining Result (b-3). The formal proof is contained in the Appendix.

\section{Discussion and Two Illustrative Examples}

These results show that the presence of uncertainties has two effects. First, uncertainty strengthens the economic attractiveness of structural measures which reduce the need for private transport. Second (and conversely), it weakens the attractiveness of technological measures which reduce pollutant emissions. This runs contrary to the arguments of economic and industrial lobbyists, who generally prefer technological measures to structural measures which can pose a threat to their economic importance or competitiveness, and who use uncertainty to support the scenarios most favourable to themselves.

The presence of irreversibilities also adds to the attractiveness of structural measures. However, these irreversibilities are not necessarily taken into account in the right way during political decision-making. Countries currently planning, for example, to invest in the extensive development of electric vehicles, like France or the Netherlands, are not making fully explicit the irreversibilities that such a plan will entail in terms of electricity supply and generation.

In the model, we presumed that the public decision-maker was simultaneously setting the rates for emission of the pollutants, conferring on him/her a high level of rationality and an advanced level of sophistication in the treatment of the externalities. In practice, decisions are often taken in a less-integrated manner; the public decision-maker only considers one single dimension of the problem at a time. This way of working means that the optimisation problem is dealt with by acting only on the proportion of private transport $\left(V_{t}\right)$, and on one of the two rates of emission ( $G_{t}$ or $P_{t}$ ) - the other rate being considered as fixed. It can be conjectured that in many cases this truncated analysis may lead to reducing private transport less than optimal policy would suggest.

In practice, truncated analyses of this nature produce even worse consequences because the respective choices of rates of emission are not so independent. For example, in the case of the 'Eco-pastille', inciting people to purchase diesel vehicles only moderately reduces GGE rates, but considerably increases local pollutant emission rates. Box 1 quantifies the environmental consequences of the Eco-pastille in terms of external costs in the EU-15. The "urban sprawl" phenomenon described in Box 2 illustrates the disastrous economic and environmental consequences of government policy that encourages single-family housing without taking the associated externalities into consideration. 


\section{Box 1: The Eco-pastille for Cars in the EU-15}

Tax policies on vehicles and fuel have proved effective in reducing the $\mathrm{CO}_{2}$ emissions of a fleet (see for example Ryan et al, 2009). Thus, the Eco-pastille or green incentive scheme operating in several European countries (Austria, Denmark, Spain, Italy, France, Portugal, the Netherlands, Sweden) bases an "environmental” tax policy solely on emissions of $\mathrm{CO}_{2}$.

In doing so, it favours the vehicles with the lowest $\mathrm{CO}_{2}$ emissions (especially diesel engines) but which produce highly damaging $\mathrm{NO}_{\mathrm{X}}$ or ultrafine particles that are particularly harmful to health. Mayeres and Proost (2001) pointed out that the cost in environmental terms of diesel vehicles was far higher than that of petrol vehicles, because of the high social cost associated with their particle emissions. The gains expected from lowering average emissions of $\mathrm{CO}_{2}$ can easily be quantified and compared with the external costs expected from extra emissions of particles (and of $\mathrm{NO}_{\mathrm{X}}$ ), ignoring the other external costs (accidents, traffic congestion, noise, landscape disturbance due to roads) which obviously remain identical.

The weighted average emission rates for urban/non-urban road journeys in EU-15 are 0.045 $\mathrm{g} / \mathrm{veh}-\mathrm{km}$ for petrol vehicles and $0.2185 \mathrm{~g} / \mathrm{veh}-\mathrm{km}$ for diesel vehicles (Infras-IWW, 2004). For $\mathrm{CO}_{2}$ emissions, the average emission rates of the current fleet are estimated at $165 \mathrm{~g} / \mathrm{km}$ for petrol vehicles and $150 \mathrm{~g} / \mathrm{km}$ for diesel vehicles.

The external cost of $1 \mathrm{~kg}$ of $\mathrm{PM}_{10}$ emitted is estimated at $€ 212$ (Infras IWW, 2004), while a tonne of $\mathrm{CO}_{2}$ is subjected to a sensitivity analysis: between $€ 20$ (a low estimate falling within the Kyoto objectives) and $€ 140$ (a high estimate yielding a reduction of 50\% in 2030).

Thus, the external costs associated with $\mathrm{CO}_{2}$ and with particles for $100 \mathrm{~km}$ travelled are $€ 1.28$ (€3.26 under the high estimate) for a petrol vehicle, compared to €4.93 (respectively €6.73) for a diesel vehicle, in other words roughly 4 (respectively 2) times less. Projecting this on the average number of kilometres travelled by a vehicle over its lifetime $(200,000 \mathrm{~km}$ according to European Union, 2007), then this represents a difference of some $€ 7,300$, rising to $€ 10,200$ if $\mathrm{NO}_{\mathrm{X}}$ emissions are included at the values given by European Union (2007). These orders of magnitude are confirmed by Mailbach et al. (2008), who perform a similar analysis simultaneously taking into account $\mathrm{NO}_{\mathrm{X}}$, non-methane volatile organic compounds (NMVOC), $\mathrm{SO}_{2}$ and $\mathrm{PM}_{10}$. Using data on emissions from the German car fleet, they obtain an external cost 4 times higher for diesel vehicles than for Euro 5-standard petrol vehicles, whatever the engine size.

So the Eco-pastille system actually provides support for the boom - and technological progress - in vehicles that create an environmental footprint, through their emissions of local pollutants (particles), which is two to four times more harmful, in exchange for a $10 \%$ gain on $\mathrm{CO}_{2}$. A paradoxical consequence of this dieselisation of the fleet is that GGEs from petrol vehicles decreased by 17\% between 1990 and 2005 for EU-15, while those from diesel vehicles increased by $83 \%$ (source EEA 2007).

The European Union recently addressed the problem by drawing up a proposal for a directive obliging the authorities in Member States, when they buy transport vehicles, to take into account not only the exploitation costs linked to energy consumption and $\mathrm{CO}_{2}$ emissions, but also those linked to $\mathrm{NO}_{\mathrm{X}}$, NMVOC and particle pollution (European Union, 2007). This 
obligation is intended to take effect from $1^{\text {st }}$ January 2012 - if indeed it is adopted. Meanwhile, certain countries are applying more judicious Eco-pastille policies. The Netherlands, for example, requires all new diesel vehicles to have a particle filter, and since 2008 some German cities (like Berlin, Cologne and Hanover) have been regulating traffic in certain zones, according to emission standards.

\section{Box 2: Urban Sprawl and the "House for $€ 15$ per Day"}

Since the beginning of the 1970s, households have been moving out of most European city centres and inner suburbs into peri-urban zones. Yet planners and environmental researchers alike point to the negative impact of this urban sprawl, which increases the length of journeys between home and workplace (see for example Bartholomew, 2007). Certain policies encouraging single-unit housing promote this phenomenon. For example, the so-called "house for $€ 15$ a day" offered in France aptly illustrates the negative consequences of a lack of overall analysis of externalities. In this box, we estimate the extent of the external effects, in terms of emissions of $\mathrm{CO}_{2}$ and particles, that this policy could generate.

The private vehicle of a household resident in a peri-urban zone travels on average 25,300 $\mathrm{km} / \mathrm{yr}$, as compared to $13,700 \mathrm{~km} / \mathrm{yr}$ for a household living in an urban or suburban area (average weighted by zones of residence, Insee, 2009). In view of the findings from Box 1 and the current composition of the French car fleet $(50 \%$ are diesel vehicles and the proportion is increasing constantly), the external cost relative to atmospheric emissions can be estimated at $€ 3,670$ over 10 years (respectively $€ 5,870$, using the upper range for a tonne of $\mathrm{CO}_{2}$ ). When the external costs linked to accidents, noise and traffic congestion ( $€ 0.0614$ per vehicle per $\mathrm{km}$, Infras IWW, 2004) are added in, the total estimate is as high as $€ 10,800$ (respectively $€ 13,000$ ) over 10 years.

Over and above the external effects, the supplementary private expenditure of someone purchasing this kind of house represents on average $€ 4,570$ over 10 years in fuel costs (Lemaître and Kleinpeter, 2009), added to which are the effects of lower energy efficiency in the home. Thus, expenditure on household energy weighted by type of heating is twice as high when the dwelling is single-unit (6.7\% of household budget) than when it is multi-unit (3.34\%) (Marcus, 2009), i.e. some €6,000 difference over 10 years according to Grosmesnil (2002).

In total, the extra cost associated with a "house for $€ 15$ a day" in a peri-urban zone is $€ 20,000$ over 10 years, and this is bound to rise with the application of the "climate and energy contribution" tax (CCE), which has not yet been implemented, but which is set to be $€ 100$ in 2030 (Conférence des experts sur la contribution Climat et Energie, 2009). It should be noted that under its affordable housing legislation, the French government intends to extend this measure to apartments, which would mitigate the analysis in this Box.

Thus, externalities linked to the effects of emissions from road transport are the object of varying uncertainties, depending of what is being evaluated: uncertainties are lessened when 
the reduction envisaged is global rather than concentrated on one pollutant. During the phase of internalisation, therefore, it is useful to think about the effects of the policy chosen: does it act on overall externalities (structural policy) or does it target only one of them (technological policy)?

\section{Conclusion}

We have analysed the choice of a policy to reduce GGEs and local pollutant emissions linked to transport in a model of sequential decision-making under uncertainty. We have looked at two types of policy, structural policies acting on overall emissions and technological policies targeting certain pollutants. We have examined the effects of the arrival of information and of the irreversibility of the policies adopted on the optimal decision. One of our findings is that jointly taking both pollutants into account weakens the attractiveness of a policy aimed at reducing local (particle) emissions alone and, instead, strengthens the attractiveness of a structural policy aimed at limiting private transport in general. Some promising avenues for future research would be to take into account explicitly the uncertainties concerning the consequences of GGEs and the costs associated with particle pollution, as well as to investigate the question of the irreversibility linked to stocking these gases.

\section{References}

Arrow, K.J. \& Fisher, A.C., 1974. Environmental preservation, uncertainty and irreversibility, Quarterly Journal of Economics, 88, 312-319.

Bartholomew, K., 2007. Land use-transportation scenario planning: promise and reality, Transportation, 4(4), 397-412.

Begg, D. \& Gray, D., 2004. Transport Policy and vehicle emission objectives in the UK: is the marriage between transport and environment Policy over?, Environmental Science \& Policy, 7, 155-163.

CAFE, 2005. Clean Air for Europe Cost Benefit Analyses: Baseline Analysis 2000 to 2020, AEAT/ED51014/ Baseline Issue 5, AEA Technology, April, 122 p.

Carballes, S., 2008. Les véhicules particuliers en France, Données et références, Avril Département Transports et Mobilité, $40 \mathrm{p}$.

Centre d'analyse stratégique, 2009. La valeur tutélaire du carbone, Final report, presided by Alain Quinet, Vol. 16, La Documentation française, Paris, 422 p.

Commissariat Général du Plan, 2001. Transports : choix des investissements et coûts des nuisances, Final Report, presided by M. Boiteux, La Documentation Française, Paris, 441 p.

Conférence des experts et de la table ronde sur la contribution Climat et Énergie (French Advisory board Conference on contribution for climate and energy), 2009. Final report, Presided by Michel Rocard, July 28th, 83 p.

Department for Transport, 1998. A New Deal for Transport: Better for Everyone. The Government's White Paper on the Future of Transport. 152 p. http://www.dft.gov.uk/adobepdf/187604/A_new_deal_for_transport_be1.pdf. Accessed 17 December 2009

Department for Transport, 2008. Delivering a Sustainable Transport System: Main Report, 
November, $41 \mathrm{p}$.

Devolder, P., 2008. Le facteur 4 : origine et pertinence, miméo.

European Environment Agency, 2000. Are we moving in the right direction?, Indicators on transport and environment integration in the EU, Environmental issues series $n^{\circ} 12$, TERM 2000,Copenhagen, February 136 p.

European Environment Agency, 2007. Annual European Community greenhouse gas inventory 1990-2005 and inventory report 2007, Technical Report No. 7/2007, May, Copenhagen, $464 \mathrm{p}$.

European Environment Agency, 2009a. EEA aggregated and gap-filled air emission dataset, Sector split of emissions of Particulates, EU-15.

European Environment Agency, 2009b. EEA aggregated and gap-filled air emission dataset, Sector share of nitrogen oxides emissions, EEA member countries.

European Union, 2007. Revised proposal for a Directive of the European Parliament and of the Council on the promotion of clean and energy efficient road transport vehicles, COM(2007) 817 final, December, 18p.

Freixas, X. \& Laffont, J-J, 1984. On the Irreversibility Effect, in Boyer, M. \& Kihlstrom, R.E., (eds), Bayesian models in Economic Theory, North Holland, Amsterdam, 149-155.

Godard, O. \& Henry, C., 1998. Les instruments des politiques internationales de l'environnement : la prévention du risque climatique et les mécanisme de permis négociables, in Bureau, D., Godard, O., Hourcade, J.-C., Henry, C. \& Lipietz, A. (eds.), Fiscalité et environnement, CAE Report, La Documentation Française, Paris.

Grosmesnil, O., 2002. La consommation d'énergie à usage domestique depuis quarante ans, Insee Première $n^{\circ} 845$.

Henry, C., 1974. Investment decisions under uncertainty: the irreversibility effect, American Economic Review, 64, 1006-1012.

Hüglin, C. \& Gehrig R., 2000. Contribution du trafic routier aux immissions de PM10 et PM2.5, summary of "Anteil des Strassenverkehrs an den PM10- und PM2.5-Immissionen NFP41/C4”, Report Nr. 801.683.d, EMPA Dübendorf, July 31th.

Infras-IWW, 2004. External costs of transport, Update study, Report, Zürich / Karlsruhe.

INSEE, 2009. Enquête Nationale Transports et Déplacements 2007-2008, Direction des statistiques démographiques et sociales.

Intergovernmental Panel on Climate Change, 2007. Contribution of Working Groups I, II and III to the Fourth Assessment Report of the Intergovernmental Panel on Climate Change, Core Writing Team: Pachauri, R.K. \& Reisinger, A., (eds.), Geneva, Switzerland, p. 104.

Lemaître, E. \& Kleinpeter, M.-A., 2009. Dépenses de carburant automobile des ménages : relations avec la zone de résidence et impacts redistributifs potentiels d'une fiscalité incitative, Études \& documents n 8, Commissariat Général au Développement Durable, June.

Mailbach, M., Schreyer, C., Sutter, D., van Essen, H.P., Boon, B.H., Smokers, R., Schroten, A., Doll, C., Pawlowska, B. \& Bak, M., 2008. Handbook on estimation of external costs in the transport sector, Version 1.1, Delft, 332 p., available at http://ec.europa.eu/transport/sustainable/2008_external_costs_en.htm.

Mayeres, I. \& Proost, S., 2001. Should diesel cars in Europe be discouraged?, Regional Science and Urban Economics, 31, 453-470.

Marcus, V., 2009. Effet sur les prix et le pouvoir d'achat des ménages, Conférence des experts CCE, July 3rd. 
Michaels, P., 2005. Shattered Consensus: The True State of Global Warming, Rowman \& Littlefield Inc., ISBN 0742549232, 304 p.

NewExt, 2004. New Elements for the Assessment of External Costs from Energy Technologies, Final Report contract ENG1-CT2000-00129, September, 333 p.

Ryan, L., Ferreira, S. \& Convery, F., 2009. The impact of fiscal and other measures on new passenger car sales and $\mathrm{CO} 2$ emissions intensity: Evidence from Europe, Energy Economics, 31, 365-374.

Samoli, E., Aga, E., Touloumi, G., Nisiotis, K., Forsberg, B., Lefranc, A., Pekkanen, J., Wojtyniak, B., Schindler, C., Niciu, E., Brunstein, R., Dodic Fikfak, M. Schwartz, J. \& Katsouyanni, K., 2006. Short-term effects of nitrogen dioxide on mortality: an analysis within the APHEA project, European Respiratory Journal, 27:6, 1129-1138.

Singer, F. (ed.), 2008. Nature, Not Human Activity, Rules the Climate, The Heartland Institute : Chicago, IL.

Who, 2005. Health effects of transport-related air pollution, Krzyzanowski, M., KunaDibbert, B. \& Schneider, J., (eds.) ISBN 928901373 7, 205 p.

\section{Appendix}

\section{Proof of Proposition 1.}

Step 1: Properties of $2^{\text {nd }}$ period choices

We denote $V_{2}^{*}, G_{2}^{*}$ and $P_{2}^{*}$ the optimal solutions of the optimisation problem

$$
J\left(V_{1} ; G_{1} ; P_{1} ; \theta ; \phi ; i ; c\right)=\underset{V_{2} \in\left[i . V_{1} ; 1\right], G_{2} \in\left[c . G_{1} ; 1\right], P_{2} \in\left[c . P_{1} ; 1\right]}{\operatorname{Min}} \operatorname{CT}\left(V_{2} ; G_{2} ; P_{2} ; \theta ; \phi\right) .
$$

These optimal solutions are functions of $\left(V_{1} ; G_{1} ; P_{1} ; \theta ; \phi ; i ; c\right)$. They satisfy the following optimality conditions:

$$
\begin{gathered}
\alpha+\beta . G_{2}+\gamma \cdot P_{2}+\theta \cdot\left(1-G_{2}\right)+\phi \cdot\left(1-P_{2}\right)-C^{\prime}\left(1-V_{2}\right)=0 \text { if } V_{2}>i . V_{1} \text { or } \\
\alpha+\beta \cdot G_{2}+\gamma \cdot P_{2}+\theta \cdot\left(1-G_{2}\right)+\phi \cdot\left(1-P_{2}\right)-C^{\prime}\left(1-V_{2}\right)=0 \text { if } G_{2}=i . V_{1} \\
\beta . V_{2}+D^{\prime}\left(G_{2}\right)-\theta \cdot V_{2}=0 \text { if } G_{2}>c . G_{1} \text { or } \beta \cdot V_{2}+D^{\prime}\left(G_{2}\right)-\theta \cdot V_{2} \geq 0 \text { if } G_{2}=c . G_{1} \\
\gamma \cdot V_{2}+E^{\prime}\left(P_{2}\right)-\phi . V_{2}=0 \text { if } P_{2}>c . P_{1} \text { or } \gamma \cdot V_{2}+E^{\prime}\left(P_{2}\right)-\phi \cdot V_{2} \geq 0 \text { if } P_{2}=c . P_{1}
\end{gathered}
$$

We show first that the $2^{\text {nd }}$ period optimal choices increase with the $1^{\text {st }}$ period choices $V_{1}, G_{1}$ and $P_{1}$.

(a) Assume $\bar{V}_{1}>V_{1}$. Let us assume that we do not have

$$
\begin{aligned}
V_{2}^{*}\left(\overline{V_{1}} ; G_{1} ; P_{1}\right) & =\overline{V_{2}^{*}} \geq V_{2}^{*}\left(V_{1} ; G_{1} ; P_{1}\right)=V_{2}^{*}, \\
G_{2}^{*}\left(\overline{V_{1}} ; G_{1} ; P_{1}\right) & =\overline{G_{2}^{*}} \geq G_{2}^{*}\left(V_{1} ; G_{1} ; P_{1}\right)=G_{2}^{*} \\
\text { and } P_{2}^{*}\left(\overline{V_{1}} ; G_{1} ; P_{1}\right) & =\overline{P_{2}^{*}} \geq P_{2}^{*}\left(V_{1} ; G_{1} ; P_{1}\right)=P_{2}^{*} .
\end{aligned}
$$

- Suppose ad absurdum that we have $\overline{V_{2}^{*}}<V_{2}^{*}, \overline{G_{2}^{*}} \leq G_{2}^{*}$ and $\overline{P_{2}^{*}} \leq P_{2}^{*}$. Then, we show that: 


$$
\alpha+\beta \cdot \overline{G_{2}^{*}}+\gamma \cdot \overline{P_{2}^{*}}+\theta \cdot\left(1-\overline{G_{2}^{*}}\right)+\phi \cdot\left(1-\overline{P_{2}^{*}}\right)-C^{\prime}\left(1-\overline{V_{2}^{*}}\right)<0
$$

Since $V_{2}^{*}>\overline{V_{2}^{*}} \geq \overline{V_{1}}>V_{1}$,

$$
\alpha+\beta \cdot G_{2}+\gamma \cdot P_{2}+\theta \cdot\left(1-G_{2}\right)+\phi \cdot\left(1-P_{2}\right)-C^{\prime}\left(1-V_{2}\right)=0
$$

Given that $\beta \leq \theta$, the assumption that $\overline{G_{2}^{*}} \leq G_{2}^{*}$ implies that

$$
\beta \cdot \overline{G_{2}^{*}}+\theta \cdot\left(1-\overline{G_{2}^{*}}\right) \leq \beta \cdot G_{2}^{*}+\theta \cdot\left(1-G_{2}^{*}\right) .
$$

Similarly, we have

$$
\gamma \cdot \overline{P_{2}^{*}}+\phi \cdot\left(1-\overline{P_{2}^{*}}\right) \leq \gamma \cdot P_{2}^{*}+\phi \cdot\left(1-P_{2}^{*}\right) .
$$

The assumption that $\overline{V_{2}^{*}}<V_{2}^{*}$ implies that $C^{\prime}\left(1-\overline{V_{2}^{*}}\right)>C^{\prime}\left(1-V_{2}^{*}\right)$. Therefore, we have:

$$
\begin{aligned}
& \alpha+\beta \cdot \overline{G_{2}^{*}}+\gamma \cdot \overline{P_{2}^{*}}+\theta \cdot\left(1-\overline{G_{2}^{*}}\right)+\phi \cdot\left(1-\overline{P_{2}^{*}}\right)-C^{\prime}\left(1-\overline{V_{2}^{*}}\right)< \\
& \alpha+\beta \cdot G_{2}^{*}+\gamma \cdot P_{2}^{*}+\theta \cdot\left(1-G_{2}^{*}\right)+\phi \cdot\left(1-P_{2}^{*}\right)-C^{\prime}\left(1-V_{2}^{*}\right)=0
\end{aligned}
$$

which proves that the optimality conditions are not satisfied.

- Note that $\overline{V_{2}^{*}}<V_{2}^{*}$ and $\overline{G_{2}^{*}}>G_{2}^{*}$ is not feasible, since then we would have

$$
\beta \cdot \overline{V_{2}^{*}}+D^{\prime}\left(\overline{G_{2}^{*}}\right)-\theta \cdot \overline{V_{2}^{*}}>\beta \cdot V_{2}^{*}+D^{\prime}\left(G_{2}^{*}\right)-\theta \cdot V_{2}^{*} \geq 0 .
$$

But since $\overline{G_{2}^{*}}>G_{2}^{*} \geq c \cdot G_{1}$, the optimality conditions imply that $\beta \cdot \overline{V_{2}^{*}}+D^{\prime}\left(\overline{G_{2}^{*}}\right)-\theta \cdot \overline{V_{2}^{*}}=0$ which contradicts the hypothesis. A similar argument can be used to prove that $\overline{V_{2}^{*}}<V_{2}^{*}$, and $\overline{P_{2}^{*}}>P_{2}^{*}$ is not feasible.

- Note that $\overline{V_{2}^{*}} \geq V_{2}^{*}$ and $\overline{G_{2}^{*}}<G_{2}^{*}$ is not feasible either, since then we would have

$$
\beta \cdot \overline{V_{2}^{*}}+D^{\prime}\left(\overline{G_{2}^{*}}\right)-\theta \cdot \overline{V_{2}^{*}}<\beta \cdot V_{2}^{*}+D^{\prime}\left(G_{2}^{*}\right)-\theta \cdot V_{2}^{*} .
$$

Because $\overline{G_{2}^{*}} \geq c \cdot G_{1}$, we have $G_{2}^{*}>c \cdot G_{1}$, and the optimality conditions imply that $\beta \cdot V_{2}^{*}+D^{\prime}\left(G_{2}^{*}\right)-\theta \cdot V_{2}^{*}=0$. We therefore have $\beta \cdot \overline{V_{2}^{*}}+D^{\prime}\left(\overline{G_{2}^{*}}\right)-\theta \cdot \overline{V_{2}^{*}}<0$, which proves that the optimality conditions cannot be satisfied. We can show that $\overline{V_{2}^{*}} \geq V_{2}^{*}$ et $\overline{P_{2}^{*}}<P_{2}^{*}$ is not feasible using a similar argument.

On the whole, we obtain that $\overline{V_{2}^{*}} \geq V_{2}^{*}, \overline{G_{2}^{*}} \geq G_{2}^{*}$ and $\overline{P_{2}^{*}} \geq P_{2}^{*}$.

(b) Assume $\overline{G_{1}}>G_{1}$. Note that if $G_{2}^{*} \geq c \cdot \overline{G_{1}}$, then $V_{2}^{*}, G_{2}^{*}$ and $P_{2}^{*}$ satisfy the optimality conditions when the first period choices are $\left(V_{1} ; \overline{G_{1}} ; P_{1}\right)$. Consequently $\overline{V_{2}^{*}}=V_{2}^{*}, \overline{G_{2}^{*}}=G_{2}^{*}$ and $\overline{P_{2}^{*}}=P_{2}^{*}$.

Let us consider the case where $c \cdot \overline{G_{1}}>G_{2}^{*} \geq c \cdot G_{1}$. Since $\overline{G_{2}^{*}} \geq c \cdot \overline{G_{1}}$, then $\overline{G_{2}^{*}}>G_{2}^{*}$. Assume that we do not have $\overline{V_{2}^{*}} \geq V_{2}^{*}$, and that instead we have $V_{1} \leq \overline{V_{2}^{*}}<V_{2}^{*}$.

Since $\gamma \leq \phi$, then

$$
\gamma \cdot \overline{V_{2}^{*}}+E^{\prime}\left(P_{2}^{*}\right)-\phi \cdot \overline{V_{2}^{*}}>\gamma \cdot V_{2}^{*}+E^{\prime}\left(P_{2}^{*}\right)-\phi \cdot V_{2}^{*}
$$


and thus $\overline{P_{2}^{*}} \leq P_{2}^{*}$. We would thus have

$$
\begin{aligned}
& \alpha \cdot \overline{V_{2}^{*}}+C\left(1-\overline{V_{2}^{*}}\right)+(\beta-\theta) \cdot \overline{G_{2}^{*}} \cdot \overline{V_{2}^{*}}+(\gamma-\phi) \cdot \overline{P_{2}^{*}} \cdot \overline{V_{2}^{*}} \\
& +D\left(\overline{G_{2}^{*}}\right)+E\left(\overline{P_{2}^{*}}\right)+(\theta+\phi) \cdot \overline{V_{2}^{*}} \\
< & \alpha \cdot V_{2}^{*}+C\left(1-V_{2}^{*}\right)+(\beta-\theta) \cdot \overline{G_{2}^{*}} \cdot V_{2}^{*}+(\gamma-\phi) \cdot P_{2}^{*} \cdot V_{2}^{*} \\
& +D\left(\overline{G_{2}^{*}}\right)+E\left(P_{2}^{*}\right)+(\theta+\phi) \cdot V_{2}^{*}
\end{aligned}
$$

whereas

$$
\begin{aligned}
& \alpha \cdot V_{2}^{*}+C\left(1-V_{2}^{*}\right)+(\beta-\theta) \cdot G_{2}^{*} \cdot V_{2}^{*}+(\gamma-\phi) \cdot P_{2}^{*} \cdot V_{2}^{*} \\
& +D\left(G_{2}^{*}\right)+E\left(P_{2}^{*}\right)+(\theta+\phi) \cdot V_{2}^{*} \\
< & \alpha \cdot \overline{V_{2}^{*}}+C\left(1-\overline{V_{2}^{*}}\right)+(\beta-\theta) \cdot G_{2}^{*} \cdot \overline{V_{2}^{*}}+(\gamma-\phi) \cdot \overline{P_{2}^{*}} \cdot \overline{V_{2}^{*}} \\
& +D\left(G_{2}^{*}\right)+E\left(\overline{P_{2}^{*}}\right)+(\theta+\phi) \cdot \overline{V_{2}^{*}}
\end{aligned}
$$

Thus, by reduction, we would have:

$$
(\beta-\theta) \cdot \overline{G_{2}^{*}} \cdot \overline{V_{2}^{*}}+(\beta-\theta) \cdot G_{2}^{*} \cdot V_{2}^{*}<(\beta-\theta) \cdot \overline{G_{2}^{*}} \cdot V_{2}^{*}+(\beta-\theta) \cdot G_{2}^{*} \cdot \overline{V_{2}^{*}}
$$

and since $\beta-\theta \leq 0$, we would have

$$
\overline{G_{2}^{*}} \cdot \overline{V_{2}^{*}}+. G_{2}^{*} \cdot V_{2}^{*} \geq \overline{G_{2}^{*}} \cdot V_{2}^{*}+G_{2}^{*} \cdot \overline{V_{2}^{*}}
$$

or

$$
\left(\overline{G_{2}^{*}}-G_{2}^{*}\right)\left(\overline{V_{2}^{*}}-V_{2}^{*}\right) \geq 0
$$

which contradicts $\overline{G_{2}^{*}}>G_{2}^{*}$ and $\overline{V_{2}^{*}}<V_{2}^{*}$. Yet, since $\overline{V_{2}^{*}} \geq V_{2}^{*}$, we also have $\overline{P_{2}^{*}} \geq P_{2}^{*}$ which proves that the $2^{\text {nd }}$ period choices increase with $G_{1}$.

A similar argument can be used to prove that the $2^{\text {nd }}$ period choices increase with $P_{1}$.

Step 2 : Property of the $2^{\text {nd }}$ period value function.

We will show that the $1^{\text {st }}$ order derivatives of the function $J\left(V_{1} ; G_{1} ; P_{1} ; \theta ; \phi ; i ; c\right)$ with respect to the $1^{\text {st }}$ period choices are positive. We have:

$$
\begin{aligned}
\frac{\partial J}{\partial V_{1}}= & \left(\alpha+\beta \cdot G_{2}^{*}+\gamma \cdot P_{2}^{*}+\theta \cdot\left(1-G_{2}^{*}\right)+\phi \cdot\left(1-P_{2}^{*}\right)-C^{\prime}\left(1-V_{2}^{*}\right)\right) \frac{\partial V_{2}^{*}}{\partial V_{1}} \\
& +\left(\beta \cdot V_{2}^{*}+D^{\prime}\left(G_{2}^{*}\right)-\theta \cdot V_{2}^{*}\right) \frac{\partial G_{2}^{*}}{\partial V_{1}}+\left(\gamma \cdot V_{2}^{*}+E^{\prime}\left(P_{2}^{*}\right)-\phi \cdot V_{2}^{*}\right) \frac{\partial P_{2}^{*}}{\partial V_{1}}
\end{aligned}
$$

If $\left(\beta \cdot V_{2}^{*}+D^{\prime}\left(G_{2}^{*}\right)-\theta \cdot V_{2}^{*}\right)>0$, then $G_{2}^{*}=c . G_{1}$ and therefore $\frac{\partial G_{2}^{*}}{\partial V_{1}}=0$. Consequently,

$$
\left(\beta \cdot V_{2}^{*}+D^{\prime}\left(G_{2}\right)-\theta \cdot V_{2}^{*}\right) \frac{\partial G_{2}^{*}}{\partial V_{1}}=0
$$

and similarly

$$
\left(\gamma \cdot V_{2}^{*}+E^{\prime}\left(P_{2}^{*}\right)-\phi \cdot V_{2}^{*}\right) \frac{\partial P_{2}^{*}}{\partial V_{1}}=0
$$


If

$$
\alpha+\beta \cdot G_{2}^{*}+\gamma \cdot P_{2}^{*}+\theta \cdot\left(1-G_{2}^{*}\right)+\phi \cdot\left(1-P_{2}^{*}\right)-C^{\prime}\left(1-V_{2}^{*}\right)>0
$$

then $V_{2}^{*}=i . V_{1}$ and therefore $\frac{\partial V_{2}^{*}}{\partial V_{1}}=i$. Thus

$$
\frac{\partial J}{\partial V_{1}}=i \cdot\left(\alpha+\beta \cdot G_{2}^{*}+\gamma \cdot P_{2}^{*}+\theta \cdot\left(1-G_{2}^{*}\right)+\phi \cdot\left(1-P_{2}^{*}\right)-C^{\prime}\left(1-V_{2}^{*}\right)\right) \geq 0
$$

Similarly, we have

$$
\begin{aligned}
& \frac{\partial J}{\partial G_{1}}=\left(\beta \cdot V_{2}^{*}+D^{\prime}\left(G_{2}^{*}\right)-\theta \cdot V_{2}^{*}\right) \cdot c \geq 0 \\
& \frac{\partial J}{\partial P_{1}}=\left(\gamma \cdot V_{2}^{*}+E^{\prime}\left(P_{2}^{*}\right)-\phi \cdot V_{2}\right) \cdot c \geq 0
\end{aligned}
$$

Step 3: Proof of proposition 1.

For $x=V, G, P, x_{1}^{*}(i ; c ; 0)=x_{2}^{*}\left(V^{*} ; G^{*} ; P^{*} ; \bar{\theta} ; \bar{\phi} ; i ; c\right)=x^{*}$ are the solutions of the following problem

$$
\underset{V_{1}, G_{1}, P_{1} \in[0 ; 1]}{\operatorname{Min}} C T\left(V_{1} ; G_{1} ; P_{1} ; \bar{\theta} ; \bar{\phi}\right)+\bar{J}\left(V_{1} ; G_{1} ; P_{1} ; \bar{\theta} ; \bar{\phi} ; i ; c ; 0\right)
$$

subject to:

$$
\begin{gathered}
\alpha+\beta \cdot G^{*}+\gamma \cdot P^{*}+\bar{\theta} \cdot\left(1-G^{*}\right)+\bar{\phi} \cdot\left(1-P^{*}\right)-C^{\prime}\left(1-V^{*}\right)=0 \\
\beta \cdot V^{*}+D^{\prime}\left(G^{*}\right)-\bar{\theta} \cdot V^{*}=0 \\
\gamma \cdot V^{*}+E^{\prime}\left(P^{*}\right)-\bar{\phi} \cdot V^{*}=0
\end{gathered}
$$

$V_{1}^{*}(i ; c ; 1 ;), G_{1}^{*}(i ; c ; 1)$ and $P_{1}^{*}(i ; c ; 1)$ satisfy the optimality conditions

$$
\begin{gathered}
\alpha+\beta \cdot G_{1}^{*}+\gamma \cdot P_{1}^{*}+\bar{\theta} \cdot\left(1-G_{1}^{*}\right)+\bar{\phi} \cdot\left(1-P_{1}^{*}\right)-C^{\prime}\left(1-V_{1}^{*}\right)+\frac{\partial \bar{J}}{\partial V_{1}}=0 \\
\beta \cdot V_{1}^{*}+D^{\prime}\left(G_{1}^{*}\right)-\bar{\theta} \cdot V_{1}^{*}+\frac{\partial \bar{J}}{\partial G_{1}}=0 \\
\gamma \cdot V_{1}^{*}+E^{\prime}\left(P_{1}^{*}\right)-\bar{\phi} \cdot V_{1}^{*}+\frac{\partial \bar{J}}{\partial P_{1}}=0
\end{gathered}
$$

Let us assume that proposition 1 is not true, and see what happens.

- First, suppose that $V_{1}^{*}(i ; c ; 1)=\overline{V_{1}^{*}}>V^{*}, G_{1}^{*}(i ; c ; 1)=\overline{G_{1}^{*}} \geq G^{*}$ and $P_{1}^{*}(i ; c ; 1)=\overline{P_{1}^{*}} \geq P^{*}$. This implies that one of the following three values

$$
\begin{gathered}
\alpha+\beta \cdot \overline{G_{1}^{*}}+\gamma \cdot P_{1}^{*}+\bar{\theta} \cdot\left(1-\overline{G_{1}^{*}}\right)+\bar{\phi} \cdot\left(1-\overline{P_{1}^{*}}\right)-C^{\prime}\left(1-\overline{V_{1}^{*}}\right) \\
\beta \cdot \overline{V_{1}^{*}}+D^{\prime}\left(\overline{G_{1}^{*}}\right)-\bar{\theta} \cdot \overline{V_{1}^{*}} \\
\gamma \cdot \overline{V_{1}^{*}}+E^{\prime}\left(\overline{P_{1}^{*}}\right)-\bar{\phi} \cdot \overline{V_{1}^{*}}
\end{gathered}
$$

is strictly positive. Since we have shown that the $1^{\text {st }}$ order derivatives of $\mathrm{J}$ are positive, then one of the optimality conditions that $V_{1}^{*}(i ; c ; 1), G_{1}^{*}(i ; c ; 1)$ and $P_{1}^{*}(i ; c ; 1)$ have to satisfy, is not satisfied. 
- $\quad$ Suppose that $V_{1}^{*}(i ; c ; 1)=\overline{V_{1}^{*}}>V^{*}, G_{1}^{*}(i ; c ; 1)=\overline{G_{1}^{*}}<G^{*}$ and $P_{1}^{*}(i ; c ; 1)=\overline{P_{1}^{*}} \geq P^{*}$. Note first that

$$
\bar{J}\left(V^{*} ; \overline{G_{1}^{*}} ; P^{*} ; \bar{\theta} ; \bar{\phi} ; i ; c ; 1\right) \leq \bar{J}\left(\overline{V_{1}^{*}} ; \overline{G_{1}^{*}} ; \overline{P_{1}^{*}} ; \bar{\theta} ; \bar{\phi} ; i ; c ; 1\right)
$$

In addition,

$$
\begin{aligned}
& \frac{\partial C T}{\partial V_{1}}\left(\overline{V_{1}^{*}} ; \overline{G_{1}^{*}} ; \overline{P_{1}^{*}} ; \theta ; \phi\right)>0 \\
& \frac{\partial C T}{\partial V_{1}}\left(V^{*} ; \overline{G_{1}^{*}} ; P^{*} ; \theta ; \phi\right)=0
\end{aligned}
$$

Therefore, because function CT is convex,

$$
C T\left(V^{*} ; \overline{G_{1}^{*}} ; P^{*} ; \theta ; \phi\right)>C T\left(\overline{V_{1}^{*}} ; \overline{G_{1}^{*}} ; \overline{P_{1}^{*}} ; \theta ; \phi\right)
$$

cannot hold.

Consequently, we have

$$
\begin{aligned}
& C T\left(V^{*} ; \overline{G_{1}^{*}} ; P^{*} ; \theta ; \phi\right)+\bar{J}\left(V^{*} ; \overline{G_{1}^{*}} ; P^{*} ; \bar{\theta} ; \bar{\phi} ; i ; c ; 1\right) \\
\leq & C T\left(\overline{V_{1}^{*}} ; \overline{G_{1}^{*}} ; \overline{P_{1}^{*}} ; \theta ; \phi\right)+\bar{J}\left(\overline{V_{1}^{*}} ; \overline{G_{1}^{*}} ; \overline{P_{1}^{*}} ; \bar{\theta} ; \bar{\phi} ; i ; c ; 1\right)
\end{aligned}
$$

which proves that the solution $\overline{V_{1}^{*}} ; \overline{G_{1}^{*}} ; \overline{P_{1}^{*}}$ is not the optimal solution.

- Similarly, if we assume that $V_{1}^{*}(i ; c ; 1)=\overline{V_{1}^{*}}>V^{*}, \quad G_{1}^{*}(i ; c ; 1)=\overline{G_{1}^{*}}<G^{*} \quad$ and $P_{1}^{*}(i ; c ; 1)=\overline{P_{1}^{*}}<P^{*}$, then we can show that

$$
\begin{aligned}
& C T\left(V^{*} ; \overline{G_{1}^{*}} ; \overline{P_{1}^{*}} ; \theta ; \phi\right)+\bar{J}\left(V^{*} ; \overline{G_{1}^{*}} ; \overline{P_{1}^{*}} ; \bar{\theta} ; \bar{\phi} ; i ; c ; 1\right) \\
\leq & C T\left(\overline{V_{1}^{*}} ; \overline{G_{1}^{*}} ; \overline{P_{1}^{*}} ; \theta ; \phi\right)+\bar{J}\left(\overline{V_{1}^{*}} ; \overline{G_{1}^{*}} ; \overline{P_{1}^{*}} ; \bar{\theta} ; \bar{\phi} ; i ; c ; 1\right)
\end{aligned}
$$

Therefore, the solution $\overline{V_{1}^{*}} ; \overline{G_{1}^{*}} ; \overline{P_{1}^{*}}$ is not optimal.

- Suppose that $V_{1}^{*}(i ; c ; 1)=\overline{V_{1}^{*}} \leq V^{*}$ and $G_{1}^{*}(i ; c ; 1)=\overline{G_{1}^{*}}>G^{*}$. Note that this assumption cannot hold, since then we would have

$$
\beta \cdot V_{1}^{*}+D^{\prime}\left(G_{1}^{*}\right)-\bar{\theta} \cdot V_{1}^{*}>0
$$

and because $\frac{\partial \bar{J}}{\partial G_{1}} \geq 0$,

$$
\beta \cdot V_{1}^{*}+D^{\prime}\left(G_{1}^{*}\right)-\bar{\theta} \cdot V_{1}^{*}+\frac{\partial \bar{J}}{\partial G_{1}}>0
$$

Similarly, $V_{1}^{*}(i ; c ; 1)=\overline{V_{1}^{*}} \leq V^{*}$ and $P_{1}^{*}(i ; c ; 1)=\overline{P_{1}^{*}}>P^{*}$ is not feasible.

End of the proof by contradiction.

\section{Proof of Proposition 2.}

We sketch out the proof for result (a). Result (b) can easily be proven using a similar argument.

Let us start with the benchmark case $i=c=0$ and $g=1$. 
We show that

$$
\begin{aligned}
& V_{2}^{*}\left(V^{*} ; G^{*} ; P^{*} ; \bar{\theta}+\varepsilon ; \bar{\phi} ; 0 ; 0\right) \leq V^{*}=V_{1}^{*}(0 ; 0 ; 1) \leq V_{2}^{*}\left(V^{*} ; G^{*} ; P^{*} ; \bar{\theta}-\varepsilon ; \bar{\phi} ; 0 ; 0\right) \\
& G_{2}^{*}\left(V^{*} ; G^{*} ; P^{*} ; \bar{\theta}-\varepsilon ; \bar{\phi} ; 0 ; 0\right) \leq G^{*}=G_{1}^{*}(0 ; 0 ; 1) \\
& P_{2}^{*}\left(V^{*} ; G^{*} ; P^{*} ; \bar{\theta}+\varepsilon ; \bar{\phi} ; 0 ; 0\right) \leq P^{*}=P_{1}^{*}(0 ; 0 ; 1) \leq P_{2}^{*}\left(V^{*} ; G^{*} ; P^{*} ; \bar{\theta}-\varepsilon ; \bar{\phi} ; 0 ; 0\right)
\end{aligned}
$$

If $c=1$, then for the first period choices $V^{*}, G^{*}, P^{*}$ the constraint is binding for $G_{2}^{*}$ at $\bar{\theta}-\varepsilon$ and for $P_{2}^{*}$ at $\bar{\theta}+\varepsilon$. We can show that

$$
\begin{aligned}
& V_{2}^{*}\left(V_{1}^{*} ; G_{1}^{*} ; P^{*} ; \bar{\theta}+\varepsilon ; \bar{\phi} ; 0 ; 1\right) \leq V_{1}^{*}(0 ; 1 ; 1) \leq V^{*} \\
& G_{2}^{*}\left(V_{1}^{*} ; G_{1}^{*} ; P^{*} ; \bar{\theta}-\varepsilon ; \bar{\phi} ; 0 ; 1\right)=G_{1}^{*}(0 ; 1 ; 1) \leq G^{*} \\
& P_{2}^{*}\left(V_{1}^{*} ; G_{1}^{*} ; P^{*} ; \bar{\theta}+\varepsilon ; \bar{\phi} ; 0 ; 1\right)=P_{1}^{*}(0 ; 1 ; 1) \leq P^{*}
\end{aligned}
$$

Similarly, if $i=1$ (with $c=0$ ), then for $V^{*}, G^{*}, P^{*}$ the constraint is binding for $V_{2}^{*}$ at $\bar{\theta}+\varepsilon$. We can show that

$$
\begin{aligned}
V_{2}^{*}\left(V_{1}^{*} ; G_{1}^{*} ; P^{*} ; \bar{\theta}+\varepsilon ; \bar{\phi} ; 1 ; 0\right) & \leq V_{1}^{*}(1 ; 0 ; 1) \leq V^{*} \\
G_{1}^{*}(1 ; 0 ; 1) & \leq G^{*} \\
P_{1}^{*}(1 ; 0 ; 1) & \leq P^{*}
\end{aligned}
$$

Lastly, if $i=1$ (with $c=1$ ), then for $V_{1}^{*}(0 ; 1 ; 1), G_{1}^{*}(0 ; 1 ; 1), P_{1}^{*}(0 ; 1 ; 1)$ the constraint is binding for $V_{2}^{*}$ at $\bar{\theta}+\varepsilon$. We can show that

$$
\begin{aligned}
& V_{1}^{*}(1 ; 1 ; 1) \leq V_{1}^{*}(0 ; 1 ; 1) \\
& G_{1}^{*}(1 ; 1 ; 1) \leq G_{1}^{*}(0 ; 1 ; 1) \\
& P_{1}^{*}(1 ; 1 ; 1) \leq P_{1}^{*}(0 ; 1 ; 1)
\end{aligned}
$$

